\title{
Informative Contagion: The Coronavirus (COVID-19) in Italian journalism
}

\author{
Concetta Papapicco ${ }^{1 *}$ \\ (iD) 0000-0003-3240-8740 SC 57208754879 AAG-1834-2019 \\ 1 University of Bari "Aldo Moro", ITALY \\ *Corresponding author: concetta.papapicco@uniba.it
}

Citation: Papapicco, C. (2020). Informative Contagion: The Coronavirus (COVID-19) in Italian journalism. Online Journal of Communication and Media Technologies, 10(3), e202014. https://doi.org/10.29333/ojcmt/7938

\section{ARTICLE INFO}

Received: 13 Mar 2020

Accepted: 9 Apr 2020

\section{ABSTRACT}

The spreading of new Coronavirus in addition to becoming a global phenomenon, following the declaration of a pandemic state, has generated excessive access to information, phenomenon named "Infodemia" (Cinelli et al., 2020). The general purpose of the exploratory study is to investigate how the coronavirus situation is described from the journalistic communication. Starting from La Repubblica online, as a reference journalistic magazine, the study assumes that if the circulation of information helps to create a social representation of the phenomenon, the excessive accessibility to sources of information (infodemia) can be modulated by the "how" the phenomenon is described by the journalists. The methodology proposed is quanti-qualitative (mixed method). A Content Analysis (Mayring, 2004) with the SketchEngine software (Thomas, 2016) is carried out first. In support, a Diatextual Analysis (Papapicco \& Mininni, 2019) was carried out. The results show the presence of the contrast vision about COVID-19 situation in Italy.

Keywords: Coronavirus, COVID-19, italian infodemia, La Repubblica online, mix method

\section{INTRODUCTION}

The spreading of new Coronavirus (COVID-19) in addition to becoming a global phenomenon, following the declaration of a pandemic state, has generated excessive access to information, sometimes not thoroughly screened, which make it difficult to navigate a given topic because of the difficulty of finding reliable sources. As a result there is a high level of contagion, understood as the spread of the virus, but also as the spread of information in a viral and harmful way, which prompted the World Health Organization to coin the term Infodemia to give "a name" the phenomenon of excessive information.

With neologism "Infodemia", the World Health Organization (OMS) wanted, in these days when fear of the coronavirus is raging, point out that perhaps the greatest danger of global society in the age of social media. This phenomenon is the distortion of reality in the rumble of echoes and comments of the global community on real or often invented facts (Cinelli et al., 2020).

The general purpose of the exploratory study is to investigate how the coronavirus situation is described from the journalistic communication. Starting from La Repubblica online, as a reference journalistic magazine, as a specific objective, the research aims to understand the way in which journalistic communication describes the phenomenon of the COVID-19 virus spread, the spread of contagion and restrictive measures of social distancing in the Italian context. The study starts from the hypothesis that if the circulation of information helps to create a social representation of the phenomenon, the excessive accessibility to sources of information (Infodemia) can be modulated by the "how" the phenomenon is described by the journalists. The methodology proposed, in fact, in the exploratory study is quanti-qualitative (mixed) method. A Content Analysis (Mayring, 2004) with the SketchEngine software (Thomas, 2016) is carried out first. In support of the Content Analysis, a Diatextual Analysis (Papapicco \& Mininni, 2019) was carried out. The Diatextual Analysis is a qualitative analysis useful to detect in the analyzed texts, that is the online articles of La Repubblica on the

Copyright $(\mathbf{2 0 2 0}$ by authors; licensee OJCMT. This article is an open access article distributed under the terms and conditions of the Creative Commons Attribution License (http://creativecommons.org/licenses/by/4.0/). 
topic of coronavirus, Subjectivity, Argomentativity and Mode (Mininni, 2013). The research focuses mainly on "Mode", or "How" are the events related to coronavirus in the online articles of La Repubblica about COVID19 phenomenon.

\section{CORONAVIRUS: SOCIO-EPIDEMIOLOGY OF VIRUS INFECTION}

Since the beginning of January 2020, the attention of the medical-scientific community and the dissemination of information is focused on the epidemic caused by the new coronavirus (SARSCoV-2) emerged in Wuhan in China at the end of 2019 and that is still spreading mainly in a vast region since the epicentre, despite the unprecedented efforts made by China to contain it. The infection caused by the new coronavirus (called COVID-19, or "coronavirus disease-2019") affects the respiratory system with a broad spectrum of symptoms: mild to very severe to high mortality due to viral pneumonia due to acute respiratory distress syndrome.

Italy has had 12.462 confirmed cases according to the Istituto Superiore di Sanità as of March 11, and 827 deaths (https://systems.jhu.edu/research/public-health/ncov/).

"The mean age of those who died in Italy was 81 years and more than two-thirds of these patients had diabetes, cardiovascular diseases, or cancer, or were former smokers. It is therefore true that these patients had underlying health conditions, but it is also worth noting that they had acute respiratory distress syndrome (ARDS) caused by severe acute respiratory syndrome coronavirus 2 (SARS-CoV-2) pneumonia, needed respiratory support, and would not have died otherwise. Of the patients who died, 42.2\% were aged 80-89 years, $32.4 \%$ were aged $70-79$ years, $8.4 \%$ were aged $60-69$ years, and $2.8 \%$ were aged $50-59$ years. The male to female ratio is $80 \%$ to $20 \%$ with an older median age for women" (World Health Organization report, 2020).

"The Italian Government implemented extraordinary measures to limit viral transmission, that intended to minimise the likelihood that people who are not infected come into contact with people who are infected. This decision is certainly courageous and important, but it is not enough. At present, the Italian national health system's capacity to effectively respond to the needs of those who are already infected and require admission to an intensive care unit for ARDS, largely due to SARS-CoV-2 pneumonia, is a matter of grave concern. Specifically, the percentage of patients admitted to intensive care units reported daily in Italy, from March 1 , up until March 11, was consistently between $9 \%$ and $11 \%$ of patients who were actively infected" (Remuzzi \& Remuzzi, 2020).

In addition to the infection of the virus, there is another type of contagion, namely information. We are witnessing, in fact, the circulation of an excessive amount of information, sometimes not carefully assessed, which make it difficult to navigate a certain subject due to the difficulty of finding reliable sources. This is a phenomenon to which the World Health Organization gives the name of "infodemia."

\section{INFODEMIC INFORMATION AND ONLINE JOURNALISM}

The information spreading can strongly influence people behavior and alter the effectiveness of the countermeasures deployed by governments. To this respect, models to forecast virus spreading are starting to account for the behavioral response of the population with respect to public health interventions and the communication dynamics behind content consumption (Kim, Fast, \& Markuzon, 2019). Social media platforms provide direct access to an unprecedented amount of content and may amplify rumors and questionable information. Taking into account users' preferences and attitudes, algorithms mediate and facilitate content promotion and thus information spreading (Shaman et al., 2013).

This shift of paradigm profoundly impacts the construction of social perceptions (Viboud and Vespignani, 2019) and the framing of narratives; it influences policy-making, political communication, as well as the evolution of public debate (Schmidt et al., 2017) especially when issues are controversial (Starnini, Frasca, \& Baronchelli, 2016). Indeed, users online tend to acquire information adhering to their worldviews (Schmidt et al., 2018), to ignore dissenting and to form polarized groups around shared narratives information (Del Vicario et al., 2016). Furthermore, when polarization is high, misinformation might easily proliferate (Bessi et al., 2015). Some studies pointed out that fake news and inaccurate information may spread faster and wider than fact-based news (Zollo et al., 2017). However, this effect might be platform-specific. 
With neologism "Infodemia" the World Health Organization (OMS) wanted, in these days when fear of the coronavirus is raging, point out that perhaps the greatest danger of global society in the age of social media is the distortion of reality in the rumble of echoes and comments of the global community on real or often invented facts (Cinelli et al., 2020). The word "Infodemia" derives from English word "Infodemic", in turn composed by the nouns "info(rmation)" and "(epi)demic".

Indeed, the infodemia is accentuated in the virtual context. Digitalisation, in fact, involves a greater influx of information sources for the users of news, but also more means available for newsmaking. The journalistic revolution of recent decades involves several factors: linguistic, the structural, the communicative process. But a revolution to be defined as such, must start from the basics. The evolution of language and technical tools is perhaps the most obvious change but it seems obvious to say how, even before these elements, also change the premises (Scarfone, 2017).

The switch from paper to digital, to online newspapers, has disintegrated from the beginning some insurmountable barriers, such as space and time, facilitating both the achievement of a wider audience, and the publication of an article, increasing access to news. As a result, it is also the style of writing, which must adapt to another context, that changes. In this case we speak of "language of online information" (Dashti, 2009) characterized by:

a) the syntheses or asydetic combinations, in which the second noun qualifies the first;

b) the ellipses, in which the adjective becomes an autonomous noun;

c) the shortening, for which a noun loses its endorsements or qualifications;

d) the metonimias or sineddochi as semantic transfers;

e) the abbreviations used;

f) the acronyms;

g) the acronyms or the fusion of two words;

h) the compositions with verbal or nominal basis;

g) the prefixes, that is the multiplication of prefixes or prefixes, nominal or adjective;

h) the suffixes, that is, the multiplication of words with the addition of particular morphemes to the base word (Ward \& Dickinson, 2002).

These innovations modify the "way" of describing a phenomenon in online journalism.

\section{THE CASE OF “LA REPUBLICA ONLINE” ABOUT COVID-19: AN EXPLORATORY STUDY}

The general purpose of the exploratory study is to investigate how the coronavirus situation is described from the journalistic communication. The territory considered for data collection is Italy, one of the first European nations to adopt social distancing measures to manage infections from COVID-19. As shown by the clicks recorded by Google Trends (Figure 1) regarding the word "coronavirus", in Italy there is a peak of informative searches after 20 February 2020.

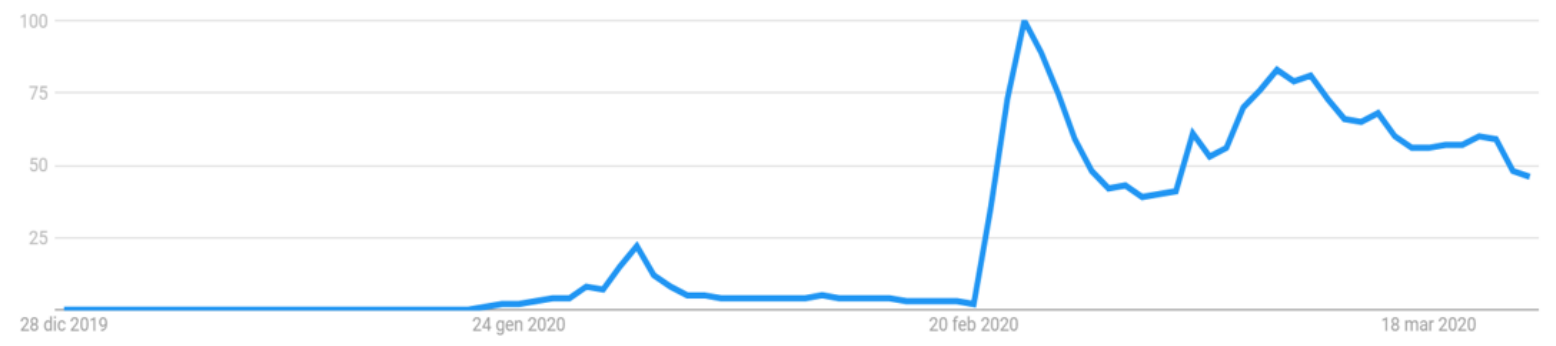

Figure 1. Italian click trends about "Coronavirus" keyword

https://trends.google.it/trends/explore?date=today\%203-m\&geo=IT\&q=coronavirus

On this basis, going to evaluate which types of "queries" have been most clicked, you can immediately notice a surge of Italian queries related to "news", as shown in Figure 2. 


\section{1 italia coronavirus}

2 coronavirus notizie

3 news coronavirus

4 ultime coronavirus

5 coronavirus ultime notizie

Figure 2. Associated Query with previous click research

https://trends.google.it/trends/explore?date=today\%203-m\&geo=IT\&q=coronavirus

From Figure 2, in fact, it emerges that the major research conducted by Italians in the period between 28 December 2019 and 29 March 2020 concerns the Italian situation on coronavirus, news on coronavirus and the latest news on coronavirus.

Starting from these data, therefore, always through the Google trends tool, it was investigated which among the major online newspapers was the most clicked in the period indicated in the search, choosing between different topics and guidelines.

The trends of several online publications have been compared, including:

1. II Sole $\mathbf{2 4}$ ore, a newspaper also present online in an economic/financial form with its historical headquarters in Northern Italy;

2. La Repubblica, also an online democratic-oriented newspaper with its historical headquarters in the capital;

3. II Quotidiano, also an online democratic-oriented newspaper with its historical headquarters in the capital;

4. Avvenire, daily present also online of Catholic inspiration born in central Italy;

5. La Stampa, journalistic magazine present also online but not politically aligned.

In the comparison of the clicks of these online newspapers, it emerges that there is a surge of research on La Repubblica, as shown in Figure 3.
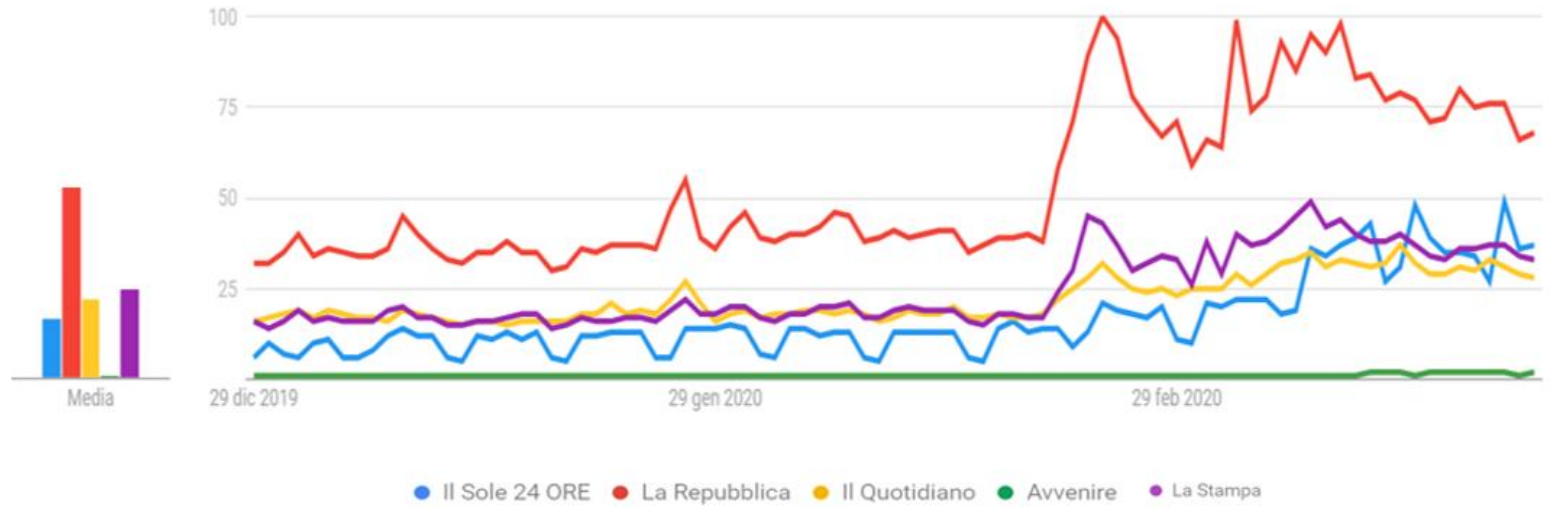

Figure 3. Interesting in time, Google Trends http://trends.google.it/trends/explore?date=today\%203m\&geo=|T\&q=\%2Fm\%2F08p|l8,La\%20Repubblica,II\%20Quotidiano,Avvenire,La\%20Stampa

The comparison, in fact, was also made region by region, with the map confirming more clicks on La Repubblica about information on coronavirus in Italy between 28 December 2019 to 29 March 2020, as shown in Figure 4. 


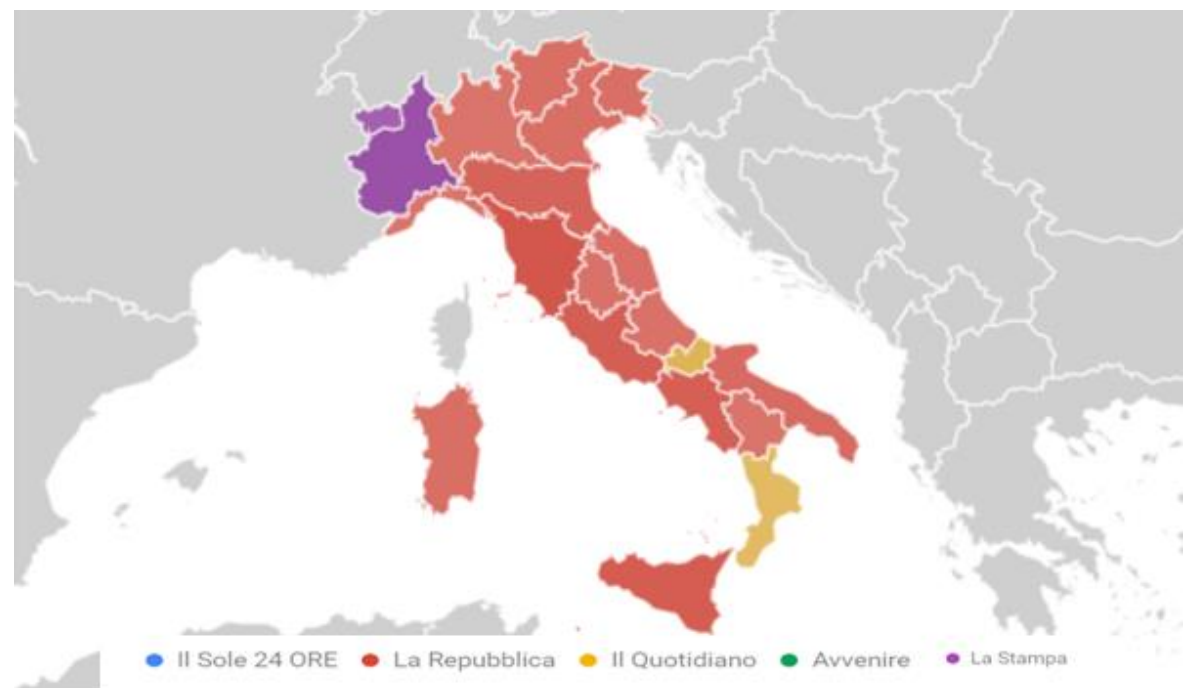

Figure 4. Interesting region by region http://trends.google.it/trends/explore?date=today\%203m\&geo=|T\&q=\%2Fm\%2F08p|I8,La\%20Repubblica,II\%20Quotidiano,Avvenire,La\%20Stampa

In the study, therefore, La Repubblica was considered as a journalistic publication for the construction of the Corpus to be analyzed.

\section{Corpus Construction}

Starting from La Repubblica online, as a reference journalistic magazine, the database "Archivio Elettronico Repubblica" was used. This is a virtual binder of all published articles by performing a basic or advanced search. The basic search works by keywords and the return by match of the items corresponding to the keyword. The advanced search, on the other hand, allows to insert, in addition to the keyword, also other filters to make the match more targeted. Examples of filter are: the period with the insertion of specific dates, the authors and whether the keyword should be contained only in the title or in the whole text. In the exploratory research, two keywords were sought: "Coronavirus" and "Covid19". It was, therefore, first carried out a basic research to explore the number of articles for the two keywords. With "coronavirus" were searched 11,118 results (https://ricerca.repubblica.it/ricerca/repubblica?query=Coronavirus\&view=repubblica). Instead, with the word "Covid19", 2.732 results (https://ricerca.repubblica.it/ricerca/repubblica?query= Covid19\&view=repubblica). This turns out to be an already quite important datum, that it explains as the journalistic magazine "defines" the virus mainly with its more known name and not with that scientific one. In the research, in fact, we have concentrated on the keyword "coronavirus", as the most practiced and has been carried out an advanced search, inserting as dates those of the surge reported by Google trends, that is 31 January 2020 as the starting date and 29 March 2020 as the end date. As for the keyword, the match was chosen on the whole text and not only on the title and the filtering was also done on articles accessible free of charge. The advanced search has returned 100 articles divided into national and regional articles. The corpus, that is the set of data that can be processed and analyzed, is the result of the advanced research on the database of archive and, therefore, the set of articles of La Repubblica online on a national and regional scale.

\section{Objectives and Methodology}

As a specific objective, the research, in an exploratory phase, aims to understand the way in which journalistic communication describes the phenomenon of the spread of the COVID-19 virus, the spread of contagion and restrictive measures of social distancing in the Italian context. The study starts from the hypothesis that if the circulation of information helps to create a social representation of the phenomenon, the excessive accessibility to sources of information (Infodemia) can be modulated by the "how" the phenomenon is described by the journalist. In this case, therefore, it becomes important to explore the discursive mode of the articles, whose meaning, emerging from the dense plot of intertwining between text and context, becomes a "Diatext" (Mininni, 1992). 
The methodology proposed, in fact, in the exploratory study is quanti-qualitative (mixed) method. A Content Analysis (Mayring, 2004) with the SketchEngine software (Thomas, 2016) is carried out first. The software, developed by Lexical Computing Limited, is a corpus manager and text analysis. The software reads any file format, from Word to .txt, pdf or allows you to copy and paste directly into the software database the corpus to be analyzed. After providing the software with the corpus for analysis, the following functions were chosen:

1. concordance search, useful in finding examples of a word form, lemma, phrase, tag or complex structure;

2. collocation search, useful in finding word co-occurrence analysis displaying the most frequent words;

3. word lists, useful to generate frequency lists which can be filtered with complex criteria.

In support of the Content Analysis, a Diatextual Analysis (Papapicco \& Mininni, 2019) was carried out. The Diatextual Analysis is a qualitative analysis useful to detect in the analyzed texts, that is the online articles of La Repubblica on the topic of coronavirus, Subjectivity, Argomentativity and Mode (Mininni, 2013). The research focuses mainly on "Mode", or "How" are the events related to coronavirus in the online articles of La Repubblica.

\section{Results}

The results of the Content Analysis using the software SketchEngine, show a frequency of words connected to the keyword "coronavirus", which determine the context in which the keyword is enunciated by journalists.

One of the functions of the software is the Keyword In Context (KWIC). This is a useful function to predict how many times the chosen keyword, i.e. "Coronavirus", appears within the enunciation context, as shown in Graph 1.

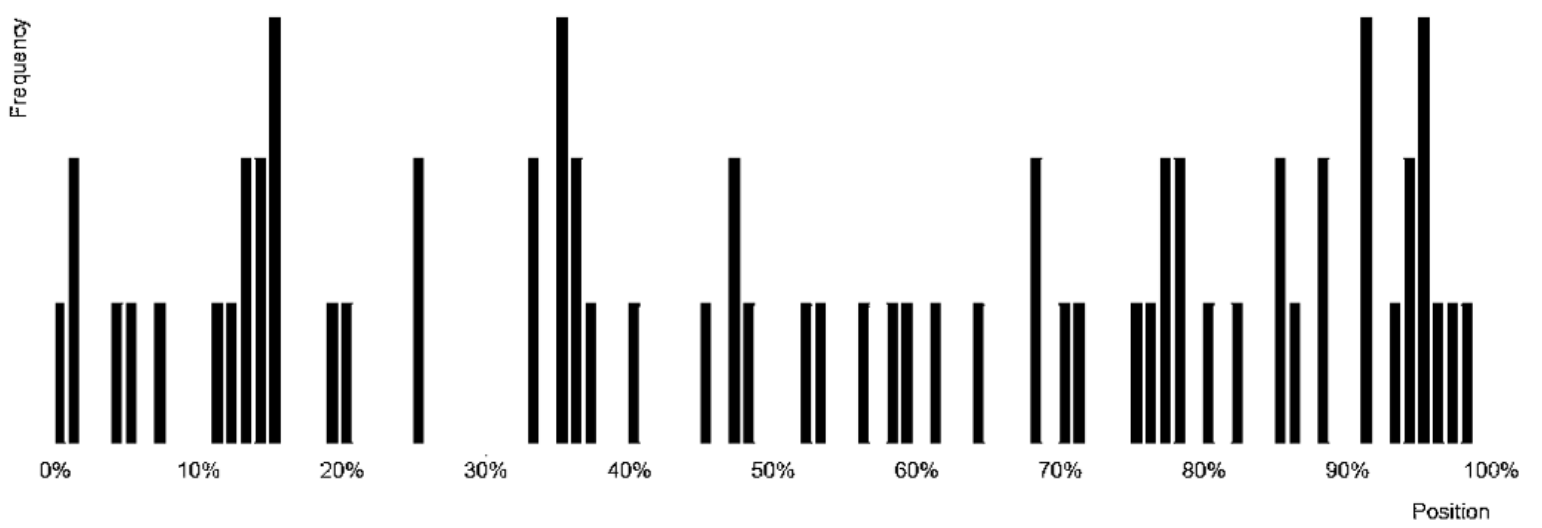

Graph 1. Distribution of KWIC

As you can see from Graph 1, the presence of the "coronavirus" keyword in the articles of La Repubblica online is most used in the latest articles corpus. This detects how not in all articles is included the coronavirus keyword in the corpus, but only in the titles. This is an important fact that allows you to increase the attractiveness and click on the news.

Going, therefore, to understand which are the contexts of enunciation of the corpus in which the word coronavirus emerges, we focus on the contextual proximity of words, adjectives and verbs. With regard to nouns, there are three contexts in which the coronavirus keyword is inserted:

1. the context of "time", where there is a high recurrence of words referring to moments in temporal terms, such as "day", "time", "hour", "night". This reference to time is an attempt to "routinize" the event in its unpredictability, giving, however, hooks to the analytics of the narrative, useful to answer to the question "When?";

2. the context of the "place", that they go in their frequency from enclosed places "house" to wide places, like the nations, that is "Italy", up to small places "Country" or "city". It is interesting to note the focus and recurrence of closed places such as "home", which takes on new meanings. The house, in fact, is often used in reference to the measures of social distancing adopted by the Italian Government. The house assumes the 
ambivalent meaning of closure and safety, but always maintaining an analytical narrative typology, answering the question "Where?";

3. the context of the "actors involved", where there is a constant contrast between figures institutionally recognized as "Minister", "President", "Mayor" and figures who refer to social roles as "doctor", "child", "father".

As shown in Table 1, where the most frequent words linked to the keyword are shown, the lemmas and frequencies are presented. More frequencies are found in the word: "day" repeated 51 times; "home" repeated 45 times; "Coronavirus" repeated 36 times; "doctor" repeated 33 times; "Italy" repeted 32 times; "hospital" repeated 31 times.

Table 1. Wordlist Frequency of Nouns

\begin{tabular}{|c|c|c|c|c|c|c|c|c|}
\hline \multirow[b]{2}{*}{1} & \multirow{2}{*}{$\begin{array}{c}\text { Lemma } \\
\text { giorno }\end{array}$} & \multicolumn{2}{|c|}{ Frequency } & \multirow{2}{*}{$\frac{\text { Lemma }}{\text { bisogno }}$} & \multicolumn{2}{|c|}{ Frequency } & \multirow{2}{*}{$\begin{array}{c}\text { Lemma } \\
\text { presidente }\end{array}$} & \multirow{2}{*}{$\begin{array}{c}\text { Frequency } \\
9\end{array}$} \\
\hline & & 51 & 35 & & 13 & 69 & & \\
\hline 2 & casa & 45 & 36 & virus & 13 & 70 & causa & 9 \\
\hline 3 & Coronavirus & 36 & 37 & modo & 13 & 71 & Bari & 8 \\
\hline 4 & medico & 33 & 38 & crisi & 13 & 72 & isola & 8 \\
\hline 5 & Italia & 32 & 39 & sindaco & 12 & 73 & domicilio & 8 \\
\hline 6 & ospedale & 31 & 40 & Refione & 12 & 74 & turno & 8 \\
\hline 7 & coronavirus & 29 & 41 & Francesco & 12 & 75 & stazione & 8 \\
\hline 8 & emergenza & 26 & 42 & euro & 12 & 76 & città & 8 \\
\hline 9 & paziente & 25 & 43 & mese & 12 & 77 & appello & 8 \\
\hline 10 & numero & 24 & 44 & ministro & 12 & 78 & scuola & 8 \\
\hline 11 & momento & 22 & 45 & azienda & 12 & 79 & sera & 8 \\
\hline 12 & persona & 22 & 46 & provincia & 11 & 80 & fase & 8 \\
\hline 13 & paese & 21 & 47 & volta & 11 & 81 & termine & 8 \\
\hline 14 & tempo & 21 & 48 & corso & 11 & 82 & direttore & 8 \\
\hline 15 & tampone & 20 & 49 & condizione & 11 & 83 & centro & 8 \\
\hline 16 & contagio & 20 & 50 & supermercato & 10 & 84 & marzo & 8 \\
\hline 17 & mascherina & 19 & 51 & mercato & 10 & 85 & fine & 8 \\
\hline 18 & lavoro & 19 & 52 & papà & 10 & 86 & Covid-19 & 8 \\
\hline 19 & attività & 19 & 53 & sicurezza & 10 & 87 & $\mathrm{II}$ & 8 \\
\hline 20 & ora & 18 & 54 & misura & 10 & 88 & maschera & 7 \\
\hline 21 & anno & 18 & 55 & Via & 10 & 89 & Palermo & 7 \\
\hline 22 & famiglia & 17 & 56 & mondo & 10 & 90 & gioco & 7 \\
\hline 23 & parte & 17 & 57 & epidemia & 10 & 91 & negozio & 7 \\
\hline 24 & cittadino & 16 & 58 & Note & 110 & 92 & prodotto & 7 \\
\hline 25 & servizio & 16 & 59 & Dato & 10 & 93 & Napoli & 7 \\
\hline 26 & pandemia & 16 & 60 & Caso & 10 & 94 & genitore & 7 \\
\hline 27 & tweet & 15 & 61 & reparto & 9 & 95 & telefono & 7 \\
\hline 28 & quaranena & 15 & 62 & ragazzo & 9 & 96 & lettera & 7 \\
\hline 29 & governo & 15 & 63 & Calo & 9 & 97 & mano & 7 \\
\hline 30 & carabiniere & 14 & 64 & Situazione & 9 & 98 & controllo & 7 \\
\hline 31 & protezione & 14 & 65 & sanità & 9 & 99 & solidarietà & 7 \\
\hline 32 & bambino & 14 & 66 & fronte & 9 & 100 & speranza & 7 \\
\hline 33 & lavoratore & 14 & 67 & realtà & 9 & & & \\
\hline 34 & settimana & 14 & 68 & rischio & 9 & & & \\
\hline
\end{tabular}

In Table 2, the main and frequent adjectives are shown at the same time as the keyword "Coronavirus". Adjectives are useful tools to polarize news towards negativity or positivity, but also to make a concept more practicable. 
Table 2. Wordlist Frequency of Adjectives

\begin{tabular}{|c|c|c|c|c|c|c|c|c|}
\hline & Lemma & Freque & & Lemma & Freque & & Lemma & Frequency \\
\hline 1 & primo & 27 & 15 & nazionale & 10 & 29 & politico & 6 \\
\hline 2 & grande & 21 & 16 & pronto & 9 & 30 & difficile & 6 \\
\hline 3 & piccolo & 19 & 17 & lungo & 9 & 31 & disponibile & 5 \\
\hline 4 & stesso & 19 & 18 & generate & 9 & 32 & Toti & 5 \\
\hline 5 & economico & 19 & 19 & regionale & 8 & 33 & superiore & 5 \\
\hline 6 & positive & 17 & 20 & alto & 8 & 34 & buono & 5 \\
\hline 7 & sanitario & 17 & 21 & pubblico & 8 & 35 & uffuciale & 5 \\
\hline 8 & C & 15 & 22 & commerciale & 7 & 36 & social & 5 \\
\hline 9 & italiano & 15 & 23 & solo & 7 & 37 & chiuso & 5 \\
\hline 10 & nuovo & 15 & 24 & attuale & 7 & 38 & diverso & 5 \\
\hline 11 & ultimo & 13 & 25 & attivo & 6 & 39 & secondo & 5 \\
\hline 12 & scorso & 12 & 26 & importante & 6 & 40 & intensivo & 5 \\
\hline 13 & necessario & 12 & 27 & personate & 6 & 41 & totale & 5 \\
\hline 14 & sociale & 10 & 28 & scientifico & 6 & & & \\
\hline
\end{tabular}

From the analysis of the most frequent adjectives, one immediately notices a logic of opposition both of placement and of semantic level. Interesting is the opposition between "big" Vs "small"; "first" Vs "last". The adjective "positive", on the other hand, has a different semantic connotation. The positivity, in this case, is related to having contracted the virus, so it assumes a negative connotation.

Also among adjectives emerges a closing perspective with adjectives such as "closed", "alone". A further contrast can be seen between "alone" and the adjectives "social". In addition to closing, there is another trend of the adjectives towards "readiness". Relevant in this context are "necessary", "intensive", "ready", "available", "official".

Also in the description of the "places" there is a contrast between "regional" and "national". There are, however, also among the adjectives references to the "scientificity" with adjectives such as "scientifical", "sanitary", "economic".

In this context, it is also important to refer to the most frequently used verbs in relation to the keyword "Coronavirus". Verbs are important to understand how the action is directed, so that in Table 3 the verbs used most frequently in the corpus collected are shown. 
Online Journal of Communication and Media Technologies, 2020

Table 3. Wordlist Frequency of Nouns

\begin{tabular}{|c|c|c|c|c|c|c|c|c|}
\hline & Lemma & Frequer & & Lemma & Freque & & Lemma & Frequency \\
\hline 1 & essere & 213 & 32 & registrare & 9 & 63 & tornare & 6 \\
\hline 2 & fare & 83 & 33 & pensare & 9 & 64 & aumentare & 6 \\
\hline 3 & avere & 57 & 34 & offrire & 9 & 65 & colpire & 6 \\
\hline 4 & potere & 50 & 35 & utilizzare & 9 & 66 & lanciare & 6 \\
\hline 5 & dovere & 37 & 36 & trovare & 9 & 67 & morire & 6 \\
\hline 6 & stare & 32 & 37 & tenere & 9 & 68 & restare & 6 \\
\hline 7 & arrivare & 27 & 38 & continuare & 8 & 69 & raccogliere & 6 \\
\hline 8 & andare & 25 & 39 & decidere & 8 & 70 & attendere & 6 \\
\hline 9 & dire & 20 & 40 & costringere & 8 & 71 & passare & 6 \\
\hline 10 & mettere & 19 & 41 & iniziare & 8 & 72 & usare & 6 \\
\hline 11 & chiedere & 17 & 42 & pagare & 8 & 73 & donare & 6 \\
\hline 12 & volere & 16 & 43 & venire & 8 & 74 & finire & 6 \\
\hline 13 & dare & 15 & 44 & sapere & 8 & 75 & effettuare & 5 \\
\hline 14 & rimanere & 14 & 45 & sembrane & 8 & 76 & guarire & 5 \\
\hline 15 & seguire & 14 & 46 & cercare & 7 & 77 & rispondere & 5 \\
\hline 16 & portare & 14 & 47 & raccontare & 7 & 78 & pubblicare & 5 \\
\hline 17 & ricevere & 13 & 48 & scoprire & 7 & 79 & rispettare & 5 \\
\hline 18 & aiutare & 12 & 49 & diventare & 7 & 80 & aspettare & 5 \\
\hline 19 & chiudere & 12 & 50 & esserejstare & 7 & 81 & esporre & 5 \\
\hline 20 & ricoverare & 11 & 51 & parlare & 7 & 82 & riportare & 5 \\
\hline 21 & lavorare & 11 & 52 & scrivere & 7 & 83 & evitare & 5 \\
\hline 22 & spiegare & 11 & 53 & lasciare & 7 & 84 & contagiare & 5 \\
\hline 23 & Partire & 10 & 54 & perdere & 7 & 85 & muovere & 5 \\
\hline 24 & vedere & 10 & 55 & aggiungere & 7 & 86 & provare & 5 \\
\hline 25 & riaprire & 10 & 56 & confermare & 7 & 87 & concludere & 5 \\
\hline 26 & chiamare & 10 & 57 & permettere & 6 & 88 & dimostrare & 5 \\
\hline 27 & servire & 10 & 58 & distribuire & 6 & 89 & mantenere & 5 \\
\hline 28 & prendere & 10 & 59 & riuscire & 6 & 90 & annunciare & 5 \\
\hline 29 & bastare & 9 & 60 & consentire & 6 & 91 & coinvolgere & 5 \\
\hline 30 & organizzare & 9 & 61 & fermare & 6 & & & \\
\hline 31 & fornire & 9 & 62 & prevedere & 6 & & & \\
\hline
\end{tabular}

The most used verbs, as can be seen from Table 3, are verbs of "state", for example "to be", used 213 times or the verb "to stay" used 31 times and the verb "to have" used 57 times. The prevalence in terms of the frequency of the state verbs bring back to highlight again a perspective of closing and static Italy in a moment of lockdown.

Through these verbs of state, the static actions linked also to the impossibility to act, as they indicate a state, a way of being, or a condition seen as a consequence of a physical or moral process, such as that of quarantine.

Also among the verbs, there is a certain regularity of opposition between:

- "to give" and "to receive"/" to offer"

- "to leave", "to stay" and "to come back"

- "to hospitalise", "to heal" and "to die"

There are instead verbs that either belong to the same semantic sphere, such as "to see" and "to predict" or verbs whose prefixes change the meaning. An example of the latter condition is "to wait" ('a-spettare') and "to comply" ('ri-spettare'). Looking at the etymology of the two Italian verbs, one immediately notices the contrast:

- 'aspettare' (to wait) derives from 'to wait' ('attendere'), the same in Latin, meaning 'to turn to', composed of ad- and tend;

- 'rispettare' (to respect), on the other hand, comes from the Latin word "respectare" which means "look back".

Important are, therefore, three modalities in which the most frequent verbs on the "coronavirus" are incardinated. 
1. attenuation: the action is carried out with reduced intensity and its (possible) effects are therefore attenuated (e.g. "suffice", "provide");

2. iteration (or repetition): the action is carried out repeatedly, at short intervals or continuously (e.g. "work", "serve");

3. speed: the speed at which the action is carried out (e.g. "increase", "organise");

Transversal to these meanings seems to be the habitual value, which often accompanies each of them (e.g. "confirm", "predict").

Also in the context of the verbs used, we note a change of perspective especially in the titles, where a Eurocentric vision is abandoned. The Eastern world is often exalted, with a focus on values such as altruism and solidarity, as in the following example:

E.g. 1 "Coronavirus, il tocilizumab scarseggia e la Cina lo regala all'Italia"

En translate "Coronavirus, tocilizumab is scarce and China gives it to Italy"

Instead, emphasis is placed on the ineffective role of Britain's emergency management plans, which have just left the European Union. A negative view of the Western world is underlined, as shown in the second example.

E.g. 2 "Londra, l'attacco di “Lancet” al governo Johnson: “Un ritardo scandaloso, abbiamo perso tempo in maniera criminale"'t

En translate "London, "Lancet" attack on Johnson's government: "A scandalous delay, we lost time in a criminal way'"'

Moving on to the semantic level, instead, the keyword "Coronavirus" is particularly linked to the word "emergency" and to the verb "to strike", as shown in Graph 2.

"Coronavirus" and/or ...

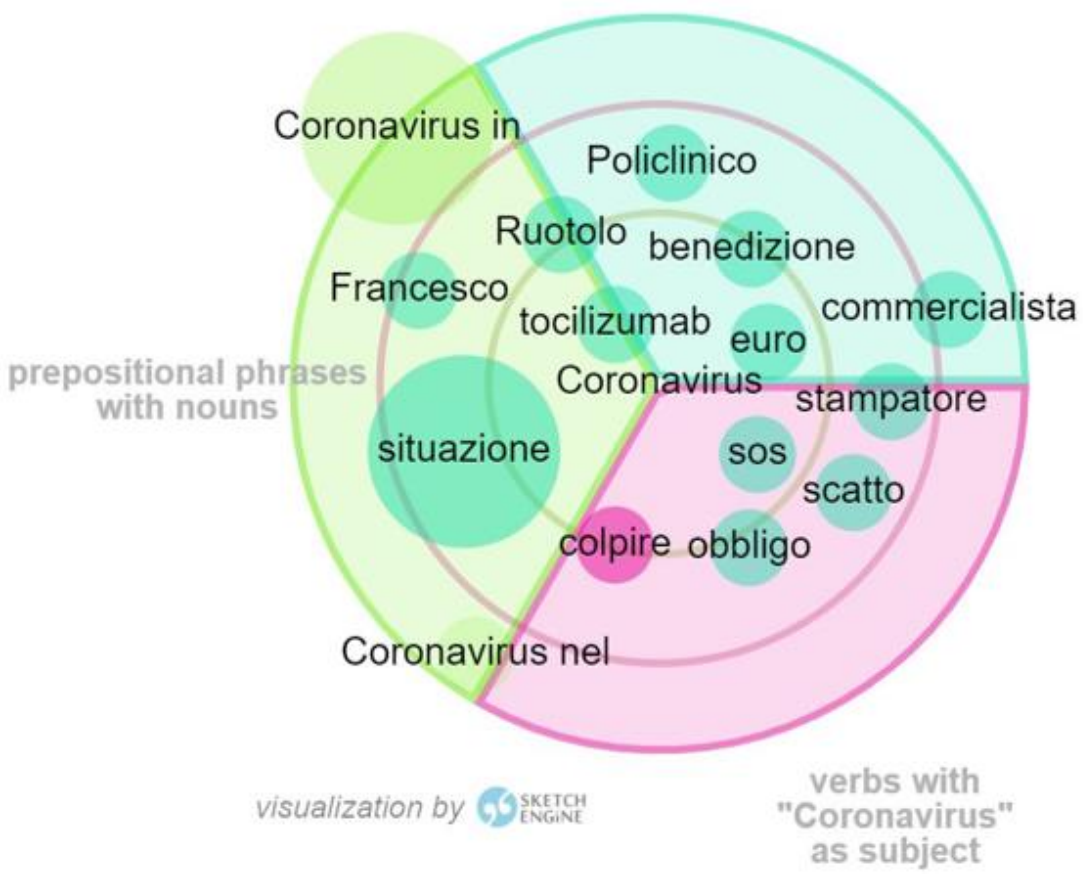

Graph 2. WordSketch about Coronavirus online journal articles

As you can see from the WordSketch, from the words of the journalists of La Repubblica online, Italy is "hit" by emergency "situation". From the other words present in the WordSketch, emerges the type of emergency described, an emergency, that is, sanitary and economic. This is evident from words like "Polyclinic" and "Tocilizumab" for the health aspect and "euro" and "sos" for the economic aspect, together with "obligation" and "accountant". Therefore, the mediated social representation that is built on the phenomenon is that Italy has been hit by a health and economic emergency, but the verb "strike" contributes to create a representation of passivity, as if this emergency is suffered and not agitated by Italy. 


\section{CONCLUSION}

The spread of coronavirus disease 2019 (COVID-19) is becoming both in terms of the spread of the virus and in terms of the production and dissemination of information. In relation to the information excessive emergency, the term "Infodemia" (Cinelli et al., 2020) has been coined, which mainly concerns the online context. The general purpose of the exploratory study is to investigate how the coronavirus situation is described from the journalistic communication. Starting from La Repubblica online, as a reference journalistic magazine, as a specific objective, the research, in an exploratory phase, aims to understand the way in which journalistic communication describes the phenomenon of the spread of the COVID-19 virus, the spread of contagion and restrictive measures of social distancing in the Italian context. The study starts from the hypothesis that if the circulation of information helps to create a social representation of the phenomenon, the excessive accessibility to sources of information (infodemia) can be modulated by the "how" the phenomenon is described by the journalist. The methodology proposed, in fact, in the exploratory study is quanti-qualitative (mixed) method. A Content Analysis (Mayring, 2004) with the SketchEngine software (Thomas, 2016) is carried out first. In support of the Content Analysis, a Diatextual Analysis (Papapicco \& Mininni, 2019) was carried out. The Diatextual Analysis is a qualitative analysis useful to detect in the analyzed texts, that is the online articles of La Repubblica on the topic of coronavirus, Subjectivity, Argomentativity and Mode (Mininni, 2013). The research focuses mainly on "Mode", or "How" are the events related to coronavirus in the online articles of La Repubblica about COVID-19 phenomenon.

The results of the exploratory study demonstrate the presence of the contrast between "unexpected event" ('emergency situation') and "attempt of routinization" which is reflected in the references to places and times, with adjectives related to closing and use of status verbs.

The fundamental aspect that prefigures the infodemia is the continuous logic of opposition of the analyzed terms. Contrast that is realized at spatial level ("regional" Vs "national") at the level of vision ("Western" Vs "Eastern") and at the level of intentionality of the action ("To Leave" Vs "To Remain"). This logic of contrast outlines the way in which the Infodemia is presented in the corpus analyzed of La Repubblica online regarding the coronavirus in Italy. The contrast, therefore, does not attenuate, but intensifies the feeling of information uncertainty and implements the construction of different social representations about the current pandemic.

Therefore, the mediated social representation that is built on the phenomenon is that Italy has been hit by a health and economic emergency, but the verb "strike" contributes to create a representation of passivity, as if this emergency is suffered and not agitated by Italy.

Among the future prospects, the research aims to extend the corpus by collecting more articles and compare the results with other Italian online newspapers more clicked.

\section{REFERENCES}

Bessi, A., Coletto, M., Davidescu, G. A., Scala, A., Caldarelli, G., \& Quattrociocchi, W. (2015). Science vs conspiracy: Collective narratives in the age of misinformation. PloS one, 10(2), e0118093. https://doi.org/10.1371/journal.pone.0118093

Cinelli, M., Quattrociocchi, W., Galeazzi, A., Valensise, C. M., Brugnoli, E., Schmidt, A. L., ... Scala, A. (2020). The COVID-19 social media infodemic. arXiv preprint arXiv:2003.05004.

Dashti, A. A. (2009). The role of online journalism in political disputes in Kuwait. Journal of Arab \& Muslim Media Research, 2(1-2), 91-112. https://doi.org/10.1386/jammr.2.1and2.91/1

Del Vicario, M., Bessi, A., Zollo, F., Petroni, F., Scala, A., Caldarelli, G., Stanley, H. E. and Quattrociocchi, W. (2016). The spreading of misinformation online. Proceedings of the National Academy of Sciences, 113(3), 554-559. https://doi.org/10.1073/pnas.1517441113

Johns Hopkins Center for Systems Science and Engineering Coronavirus COVID-19 Global Cases. Retrieved on 11 March 2020 from https://systems.jhu.edu/research/public-health/ncov/

Kim, L., Fast, S. M., \& Markuzon, N. (2019). Incorporating media data into a model of infectious disease transmission. PloS one, 14(2). https://doi.org/10.1371/journal.pone.0197646

Mayring, P. (2004). Qualitative content analysis. A companion to qualitative research, 1, 159-176.

Mininni, G. (1992). Diatesti. Napoli: Liguori. 
Mininni, G. (2013). Psicologia culturale discorsiva. Milano: Franco Angeli.

Papapicco, C., \& Mininni, G. (2019). “BR... EXIT". A Diatextual Analysis of Public Discourse on Migrant Italian Talents. Critical Approaches to Discourse Analysis Across Disciplines, 11(2).

Remuzzi, A., \& Remuzzi, G. (2020). COVID-19 and Italy: what next?. The Lancet. https://doi.org/10.1016/S01406736(20)30627-9

Scarfone, G. (2017). Giornalismo e social network: un'analisi linguistica. Lingue e culture dei media, 1(1), 44-89.

Schmidt, A. L., Zollo, F., Del Vicario, M., Bessi, A., Scala, A., Caldarelli, G., Stanley, H. E., \& Quattrociocchi, W. (2017). Anatomy of news consumption on Facebook. Proceedings of the National Academy of Sciences, 114(12), 3035-3039. https://doi.org/10.1073/pnas.1617052114

Schmidt, A. L., Zollo, F., Scala, A., Betsch, C., \& Quattrociocchi, W. (2018). Polarization of the vaccination debate on Facebook. Vaccine, 36(25), 3606-3612. https://doi.org/10.1016/j.vaccine.2018.05.040

Shaman, J., Karspeck, A., Yang, W., Tamerius, J., \& Lipsitch, M. (2013). Real-time influenza forecasts during the 2012-2013 season. Nature communications, 4(1), 1-10. https://doi.org/10.1038/ncomms3837

Starnini, M., Frasca, M., \& Baronchelli, A. (2016). Emergence of metapopulations and echo chambers in mobile agents. Scientific reports, 6, 31834. https://doi.org/10.1038/srep31834

Thomas, J. (2016). Discovering English with Sketch Engine: a corpus-based approach to language exploration. Workbook and glossary. Brno: Versatile. ISBN 9788026095798. Andrea Baronchelli. The emergence of consensus: a primer. Royal Society open science, 5(2), 172189, 2018. https://doi.org/10.1098/rsos.172189

Viboud, C., \& Vespignani, A. (2019). The future of influenza forecasts. Proceedings of the National Academy of Sciences, 116(8), 2802-2804. https://doi.org/10.1073/pnas.1822167116

Ward, M., \& Dickinson, A. (2002). Journalism online. Taylor \& Francis.

Zollo, F., Bessi, A., Del Vicario, M., Scala, A., Caldarelli, G., Shekhtman, L., Havlin, S., \& Quattrociocchi, W. (2017). Debunking in a world of tribes. PloS one, 12(7). https://doi.org/10.1371/journal.pone.0181821

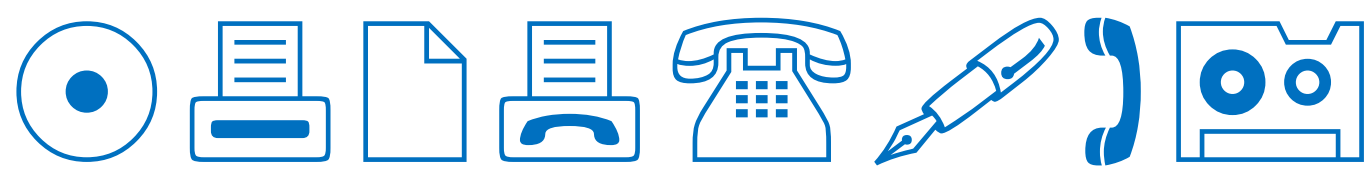

